\title{
Recurrent Herpetic Stromal Keratitis in Mice: A Model for Studying Human HSK
}

\author{
Patrick M. Stuart ${ }^{1}$ and Tammie L. Keadle ${ }^{2}$ \\ ${ }^{1}$ Department of Ophthalmology, Saint Louis University School of Medicine, 1402 S. Grand Blvd., Schwitalla Hall, \\ Room M99, St. Louis, MO 63104-1004, USA \\ ${ }^{2}$ Department of Biology, Washington University School of Medicine, St. Louis, MO 63104, USA
}

Correspondence should be addressed to Patrick M. Stuart, pstuart2@slu.edu

Received 16 December 2011; Revised 20 February 2012; Accepted 20 February 2012

Academic Editor: Lbachir BenMohamed

Copyright ( $) 2012$ P. M. Stuart and T. L. Keadle. This is an open access article distributed under the Creative Commons Attribution License, which permits unrestricted use, distribution, and reproduction in any medium, provided the original work is properly cited.

Herpes simplex virus 1 (HSV-1) infection of the cornea leads to a potentially blinding disease, termed herpetic stromal keratitis (HSK) that is characterized by lesions of an immunoinflammatory nature. In spite of the fact that HSK typically presents as a recurrent disease due to reactivation of virus which latently infects the trigeminal ganglia, most murine studies of HSK have employed a primary and not recurrent model of the disease. This report documents the several recurrent models of HSK that have been developed and how data generated from these models differs in some important aspects from data generated following primary infection of the cornea. Chief among these differences is the fact that recurrent HSK takes place in the context of an animal that has a preexisting anti-HSV immune response, while primary HSK occurs in an animal that is developing such a response. We will document both differences and similarities that derive from this fundamental difference in these models with an eye towards possible vaccines and therapies that demonstrate promise in treating HSK.

\section{Opening Comments}

Herpetic stromal keratitis (HSK) is a potentially blinding corneal inflammation that accompanies herpes simplex virus type 1 (HSV-1) infection of the eye. The disease course in HSK begins with a primary infection by HSV followed by a period during which the virus enters latency in sensory and autonomic ganglia. Many studies have shown that clinical disease is the result of a cocktail of inflammatory cells, consisting of PMN's, macrophages, and T cells (both $\mathrm{CD} 4^{+}$and $\mathrm{CD} 8^{+}$) that are recruited to the corneas of patients with HSK [1-4].

Most animal studies of HSK have focused on primary ocular infection. The major drawback with extrapolating data from primary HSV infection in mice is that it often does not manifest corneal lesions characteristic of human primary or recurrent HSK [5]. We believe that there are four advantages in using a recurrent model of HSK. The first is that recurrent human disease is most often associated with corneal scarring $[6,7]$. Second, the clinical profile in the murine recurrent model mimics many of the symptoms observed in human disease [8]. Namely, that primary infection resulted in multiple epithelial dendrites, followed by diffuse stromal opacification, while recurrent infection presented clinical features that included microdendrites, focal stromal opacities, disciform endotheliitis, and corneal neovascularization, which were more similar to those observed in human disease. Third, the model allows reactivation to occur in the context of an immune host. This is also the case in humans where disease takes place in a host that has developed an adaptive immune response against HSV-1. While it is not suggested that such adaptive responses will be identical, they will likely be more similar than extending what occurs following primary infection, where an adaptive response is initially developing (most murine studies), to what is taking place in an "immune host" following reactivation. Finally, a recurrent model lends itself to testing the efficacy of HSV vaccines. Since human disease typically occurs following reactivation, identifying vaccines that are effective when used therapeutically would be very valuable 
and a recurrent model allows for that evaluation. This is critical as many vaccines which show efficacy in primary HSK models fail when tested in a reactivation paradigm [9].

There are several different protocols that have been used to reactivate mice from latency. One of the first methods used to reactivate mice latently infected was treating mice with the immunosuppressive drug cyclophosphamide (CycloP) [10]. Later Shimeld et al. developed a model in which mice are infected with the McKrae strain of HSV-1 and given passive immunization in the form of pooled serum. The eyes of these latently infected mice are exposed to UV-B irradiation at least 30 days following primary infection to induce reactivation [11-14]. The reason for the addition of passive immunization is that this reduced the high incidence of mortality and also prevented acute HSK, which would lead to permanent corneal damage [13]. It was also noted that the latent infection was restricted to the ophthalmic part of the trigeminal ganglia [13]. When Shimeld et al. [12] and later Laycock et al. [14] compared UV-B irradiation to CycloP + dexamethasone, the incidence of virus shedding from the cornea was greater for the UV-B-treated mice and recurrent disease did was more easily apparent in UV-B-treated mice [12]. Different virus strains were compared for their ability to reactivate, and the McKrae strain of HSV-1 demonstrated the most consistent reactivation phenotype [11-13]. In addition, various strains of mice have been tested for their ability to reactivate following UV-B irradiation and the NIH strain of mice consistently displays the highest rate of reactivation (70-90\%) as determined by detection of infectious virus in tear film $[9,14,15]$. In addition, severity of disease also varies between different mouse strains with $\mathrm{NIH}$ and $\mathrm{BALB} / \mathrm{c}$ mice showing severe disease and C57BL/6 mice with much less disease $[9,15,16]$. Other investigators have also developed other means of reactivating a latent HSV-1 infection by using hyperthermia shock $[17,18]$ and most recently sodium butyrate [19]. The hyperthermia shock model is used to determine reactivation within the infected ganglion neurons and thus is a very good model to study molecular events that occur there following reactivating stress $[17,18]$. However it has not been exploited to study corneal disease. The sodium butyrate model, which does result in viral shedding from the corneal surface [19], has also not been exploited to study corneal disease. Thus, while each of these techniques has their own distinct advantages and disadvantages, the UV-B model has been used much more extensively for pathogenic and immunological studies of recurrent HSK. Thus this paper will restrict itself to the reactivation model whereby UV-B light is used to reactivate virus from latency. This was chosen as the vast majority of data concerning the pathogenesis of recurrent disease has used that model.

As a basis for comparison, a few factors should be mentioned. The first being that different investigators use a variety of strains of HSV-1 when studying primary HSK. The virus strains that have been used for these studies include, but are not restricted to, $\operatorname{RE}[4,20,21]$, Strain 17 [19], McKrae [8, 15, 22], CH394 [23], and KOS [15, 24]. In addition to a variety of HSV-1 strains being used, various mouse strains have also been used for these studies. Most studies employ C57BL/6 or BALB/c mouse strains or gene-targeted mice that are bred to these two strains. It should be noted that while infections with these various strains of HSV-1 display differences in corneal pathology and neurovirulence, the immunological components of corneal disease are remarkably similar when compared on the basis of virus strain used or the strain of mouse being infected as the following discussion will illustrate.

\section{Characteristics of Herpetic Stromal Keratitis}

As previously mentioned, HSK is at its core an inflammatory disease with chemokines involved in migration of leukocytes to sites of infection and inflammation $[25,26]$ and cytokines responsible for the activation of cells which mediate the cellular destruction following their activation. Primary models have shown that during disease, a diverse set of host inflammatory cells infiltrate the cornea following HSV-1 infection. Included among these cells are macrophages $[8,9]$, natural killer cells [27], T cells [8, 20, 28-33], polymorphonuclear neutrophils (PMNs), which are the predominant cell type early during primary infection with HSV-1 $[34,35]$, and corneal Langerhans Cells [36]. While the exact mechanism for primary HSK has not been conclusively determined, the disease is believed to be the result of the interaction of virus and host immune cells and components and not due to direct viral cytolysis of corneal cells [23]. Since much fewer studies have employed the recurrent model, even less is known about the mechanisms responsible for recurrent HSK.

\section{Role of Chemokines in HSK}

Chemokines are important factors in viral infections [37] and HSK $[21,38-40]$. These are small proteins which are made by resident tissue cells and/or immunocompetent cells and whose primary function is to direct the movement or chemotaxis of cells that bear receptors for the chemokine that is being produced. Thus during infection chemokines are released by cells at the site of infection to activate the migration of particular cells bearing appropriate chemokine receptors to that site of infection. Chemokines have also been implicated in activation and polarization of certain immunocompetent cells [41]. Due to these activities, they are potential targets for therapeutic intervention to reduce or prevent disease (see Table 1 for cells responsive to chemokines and references related to HSK). During primary HSK it has been shown that the production of IL- 6 stimulates resident corneal cells to produce CCL3 and CXCL2 [42]. Studies have shown that targeting of CCL3 significantly reduces disease $[39,43]$, suggesting that it plays a role in corneal pathology during primary HSK. In contrast, when CCL3 is neutralized or absent during recurrent HSK, the resulting disease is worse [40]. Likewise, targeting CCL2 reduced primary [44-46] but did not affect recurrent disease [40]. Eo et al. [45] coimmunized mice with a plasmid encoding $\mathrm{gB}$ of $\mathrm{HSV}$ along with various plasmids containing CCL1, CCL3, CCL4, and CXCL2, which are known to be produced by the cornea $[42,45,47]$, to determine if the adaptive immune response generated was affected by the 
TABLe 1

\begin{tabular}{lcc}
\hline Chemokine & $\begin{array}{c}\text { Chemotactic } \\
\text { activity }\end{array}$ & Reference to HSK \\
\hline CCL1 (Kit ligand) & $\begin{array}{c}\text { Monocytes, } \\
\text { NK cells, DC } \\
\text { Monocytes, T } \\
\text { cells, DC } \\
\text { CCL2 (MCP-1) }\end{array}$ & {$[45]$} \\
CCL3 (MIP-1 $\alpha)$ & $\begin{array}{c}\text { Neutrophils } \\
\text { Monocytes, }\end{array}$ & {$[39,40,42,43,45,48]$} \\
CCL4 (MIP-1 $\beta)$ & $\begin{array}{c}\text { NK cells } \\
\text { Eosinophils, }\end{array}$ & {$[45]$} \\
CCL5 (Rantes) & $\begin{array}{c}\text { NK cells, T } \\
\text { cells }\end{array}$ & {$[48]$} \\
CXCL1 (KC) & $\begin{array}{c}\text { Neutrophils } \\
\text { CXCL2 (MIP-2) }\end{array}$ & $\begin{array}{c}\text { Neutrophils } \\
\text { Monocytes, }\end{array}$ \\
CXCL10 (IP-10) & $\begin{array}{c}\text { NK cells, T } \\
\text { cells, DC }\end{array}$ & {$[47,49]$} \\
& {$[50-52]$} \\
\hline
\end{tabular}

presence of specific chemokines. Their data indicates that the chemokines CCL1 and CCL4 biased immunity to a Th2-like response, while CXCL2 and CCL3 activated a Th1 response. Mikloska et al. observed increased levels of CCL4 and, to a lesser extent, CCL3 and CCL5 in human vesicle fluid from patients with herpetic corneal lesions [48]. Similar studies evaluating CXCL1 expression have shown that infection of corneal-derived cells with HSV-1 leads to significant increases in CXCL1 production, which stimulates neutrophil chemotaxis $[47,49]$. It has been reported that CXCL10 is very important in recruiting activated T cells into sites of inflammation [50]. However, CXCL10 has been shown to be a mediator of IL-12-mediated antiangiogenesis during primary HSK $[51,52]$. Thus it is possible that CXCL10 might be involved in both promoting disease, by attracting activated $\mathrm{CD} 4^{+} \mathrm{T}$ cells, and in preventing disease by inhibiting corneal angiogenesis. The role of murine CXCL1, CXCL10, and IL-6 play during recurrent HSK has not been determined; however, they are currently being investigated in our laboratory at this time.

\section{Cytokine Profile Expressed during HSK}

In addition to chemokines, HSK is also the result of the action of various cytokines. Some of these cytokines (IL-1, IL-6, IL-17, and TNF $\alpha$ ) are found early following virus infection $[38,53-55]$ and some (IL-1 and TNF $\alpha$ ) found shortly after reactivation [56]. Staats and Lausch detected increased levels for proinflammatory cytokines, IL- $1 \alpha$, and IL-6 following primary HSV-1 infection [53]. In addition, targeting IL-1 during primary HSV-1 significantly reduced disease indicating its central role following acute infection [54]. During recurrent HSK our laboratory also detected significant increases in both IL-1, and TNF $\alpha$ [56]. Furthermore, when these cytokines were neutralized in vivo, they were shown to be required for the development of recurrent HSK [56].
Following this proinflammatory period, a somewhat overlapping set of cytokines (IFN- $\gamma$, IL-12, IL-17, IL-4 and IL-10) are found later during primary HSK $[38,53,54,57$, 58], while during this same time period recurrent HSK the cytokines IFN- $\gamma$, IL-12, IL-4, and IL-10 are reported to be expressed [59-61]. These cytokines can be very informative as they will be indicative of the phenotype of the $\mathrm{T}$ cell that is orchestrating the response at that time point. The profile of cytokines made by antigen-specific $\mathrm{T}$ cells in an immune response indicates whether it is mediated by Th1, Th2, or Th17 T cells. A Th1 response is characterized by the production of IL-2, IL-12, and IFN- $\gamma$ [62], Th2 cells produce IL-4, IL-5, IL-6, and IL-10 [62], while Th17 cells produce IL-17A, IL-17F, and IL-22 [63]. It has been reported that significant levels of IFN- $\gamma$, IL-2, and TNF- $\alpha / \beta$, but not IL- 4 or IL-10, are found in mouse corneas with primary HSK, suggesting that $\mathrm{CD} 4^{+} \mathrm{T}$ cells in the eye are Th1 [31]. Similar conclusions were derived from studies demonstrating that treatment with anti-IFN- $\gamma$ and anti-IL-2 antibodies, but not with anti-IL- 4 antibodies, protected mice from primary HSK [64]. It has been reported that IL-2 not only stimulates Th1 development but also is chemotactic for and maintains the viability of polymorphonuclear neutrophils [65], which are an early component of primary HSK $[34,35]$. Further evidence supporting Th1 cell involvement comes from studies using STAT4 KO mice [66]. STAT4 is a transcription factor that is activated by the presence of IL-12 and directs the polarization of $\mathrm{T}$ cells to become Th1 cells $[67,68]$. When infected with HSV-1, these STAT4 KO mice did not develop significant primary HSK lesions, though they were more susceptible to developing encephalitis [66]. In contrast to these results, it has been shown that when IFN- $\gamma$ KO mice were used to confirm the role of this cytokine during primary HSK surprisingly displayed similar disease to that seen in wild-type mice [67]. This was surprising as one would have expected that such mice would display less corneal disease as IFN- $\gamma$ is an integral cytokine associated with Th1 responses $[62,68]$. Interestingly, a very similar phenotype was observed in mice undergoing recurrent HSK [69]. In these studies both IFN- $\gamma$ KO mice and wild-type mice treated with antiIFN- $\gamma$ were subjected to recurrent HSK and the disease was indistinguishable from recurrent HSK in control antibodytreated wild-type mice [69].

In a completely different set of studies to determine the role of IL-10 during HSK, it was reported that intraocular treatment of mice with IL-10 reduced corneal disease from $95 \%$ to $36 \%[43,70]$. This treatment, while not effecting the production of IL- $1 \alpha$ in the cornea, led to a 10 -fold reduction in IL-2 and a 50-fold reduction in IL-6 [70]. It has also been reported that IL-10 DNA administration during primary HSK significantly reduced disease [71]. Our laboratory also evaluated the role that IL-10 plays during recurrent HSK, and similar to what was reported during primary $\operatorname{HSK}[43,70]$, lack of IL-10, as determined by neutralizing IL-10 or using IL-10 KO mice, resulted in very severe corneal disease [72]. Furthermore, treating mice with recombinant IL-10 led to significantly reduced corneal disease [72]. Taken together, these studies, both in primary HSK and recurrent HSK, 
demonstrate that IL-10 is associated with amelioration of disease [72].

Within the past several years, a new T-cell player has been added to the mix, namely, Th17 cells. These cells were termed Th17 because of their production of the cytokine IL-17 [63]. They have been shown to be involved in autoimmunity and host defense [63]. It was first reported that mice lacking IL17 receptor displayed reduced neutrophil infiltrate and less corneal disease [73]. This observation was followed by a report that showed that treatment with Resolvin E1 reduced clinical disease and at the same time reduced the numbers of both Th1 and Th17 cells in the cornea [74], further indicating that Th17 cells might be playing a role in primary HSK. That role was further supported when IL-17 KO mice and wild type mice treated with neutralizing antibodies were infected with HSV-1. These studies demonstrated that primary HSK was significantly inhibited thus indicating that both Th1 and Th17 cells likely act in concert to produce the corneal lesions seen during primary HSK [54]. The role that Th17 cells, and thus the cytokine IL-17, play in recurrent HSK has yet to be evaluated.

\section{T-Cell Functions during HSK}

As the aforementioned research implies, $\mathrm{T}$ cells are critical to the development of corneal lesions during both primary and recurrent HSK. In fact, T-cell deficient mice do experience HSK [28], unless $\mathrm{T}$ cells are adoptively transferred [29]. During primary HSK, the preponderance of data suggests that $\mathrm{CD} 4^{+} \mathrm{T}$ cells of the Th1 subset are the likely mediators of disease $[30,31,64,70,71]$ while $\mathrm{CD} 8^{+} \mathrm{T}$ cells play a minor role in disease $[22,30,31,33,75]$ or possibly are involved in reducing disease [15]. Studies attempting to determine if the classical CD4 ${ }^{+} \mathrm{FoxP}^{+} \mathrm{T}_{\text {reg }}$ cells are involved in reducing corneal disease have not conclusively demonstrated that they do so in vivo [4]. Another means of determining the functional role of T cells is the measurement of DTH responses, which are most often mediated by the Th1 subset of $\mathrm{CD}^{+}{ }^{+} \mathrm{T}$ cells. Using this readout, decreased disease is most often associated with reduced DTH responses [76, 77], though in one case where both Th1 and Th2 responses were allowed to develop, HSK was reduced, but DTH was unaltered [78]. During recurrent HSK, the T-cell profile is somewhat different. Whether by targeting these T-cell subsets by antibody depletion or by using CD4KO and CD8KO mice, these mice expressed a decreased HSK disease phenotype as compared to wild-type and untreated mice [79]. Thus it would appear that both $\mathrm{CD} 4^{+}$and $\mathrm{CD} 8^{+} \mathrm{T}$ cells contribute to clinical disease during recurrent HSK [79]. In addition, when the cytokine pattern was investigated, both Th1 and Th2 cytokines were present in the cornea shortly following reactivation [60]. These results should not be surprising as it should be recalled that recurrent HSK occurs in mice that have developed an immune response against HSV-1. That immune response will include antigen-specific $\mathrm{CD}^{+}{ }^{+} \mathrm{T}$ cells of both Th1 and Th2 subsets as well as HSV-1specific $\mathrm{CD}^{+} \mathrm{T}$ cells. Thus the mixed T-cell infiltrate may, at least in part, explain why focal stromal opacities, rather than the diffuse opacity, as typically seen in primary HSK, characterize recurrent HSK in mice [8]. That said, while there is a report implicating cytotoxic $\mathrm{T}$ cells in primary disease [80], recurrent disease is most often associated with strong DTH responses $[72,81]$.

Since $\mathrm{T}$ cells clearly play a central role in mediating disease, identifying those factors that are involved in their activation is very important. A critical factor for activation of $\mathrm{T}$ cells is the engagement of costimulatory molecules. The best characterized of these costimulatory interactions are between CD28 or CTLA- 4 on the T cell and B7-1 or B7-2 expressed by the APC [82]. Studies have shown that blocking the CD28 interaction with CTLA-4Ig significantly reduced primary HSK by inhibiting Th1 but not Th2 cells [83]. When only B7-2 was blocked, there was a significant reduction in $\mathrm{CD}^{+}$cytotoxic T-cell response and these mice experienced delayed viral clearance at the cornea [84]. However, these treated mice did not display an impact on corneal disease, suggesting that naïve $\mathrm{CD} 4^{+} \mathrm{T}$ cells are being costimulated via B7-1 [84]. The Hendricks laboratory demonstrated that targeting the CD40-CD154 interaction changed the cellular nature of the inflammatory response but did not result in reduced primary HSK [85], while targeting the OX40OX40L interaction did not significantly alter primary HSK in any way [86]. When the CD137-CD137L costimulatory pathway was targeted, reduced primary HSK was observed [87]. However, it is interesting to note that this same group later demonstrated that this interaction led to increased $\mathrm{CD} 8^{+} \mathrm{T}$-cell responses that better controlled HSV-1 infection of the skin [88]. We are currently addressing the role that costimulation plays in recurrent HSK. We hypothesize that since recurrent HSK occurs in an animal that possesses an anti-HSV-1 immune response, we believe that CD28mediated costimulation will primarily be associated with the initial T-cell activation that occurs shortly after infection and likely is not involved in subsequent stimulation of preexisting anti-HSV-1 T cells that will be present when reactivation of virus from latency occurs. However, it is possible that other costimulatory interactions that occur subsequent to CD28 activation might be important in recurrent HSK. It will be those interactions (CD40-CD154 and CD137-CD137L) that are the focus of ongoing studies in our laboratory.

\section{Role of T Cells in Maintaining Viral Latency}

In addition to their role in mediating corneal disease, $\mathrm{T}$ cells have also been implicated in maintaining viral latency in the infected trigeminal ganglia (TG). This role for T cells comes primarily from work done in the laboratory of Robert Hendricks, who reported that $\mathrm{CD} 8^{+} \mathrm{T}$ cells surround latently infected TG neurons in mice infected with HSV-1 [89-92]. In a similar fashion, clinical studies performed on recently deceased individual who know to have infections with HSV1 , found both $\mathrm{CD}^{+}$and $\mathrm{CD} 4^{+} \mathrm{T}$ cells surrounding neurons that are also stained for HSV-1 antigens [93, 94]. These cells expressed surface markers indicating that they were late effector memory T cells. As was seen in mice, they expressed granzyme markers but no cytolytic function was detected 
[94]. It has since been reported in murine studies that the production of IFN $\gamma$, granzyme, and perforin by $\mathrm{T}$ cells is important to this maintenance of latency $[95,96]$. It was further shown that these infected neurons were not undergoing apoptosis, but that the target of granzyme B released by T cells was the HSV-1 immediate early protein, ICP4 [95], which is essential for further viral gene expression and thus production of infectious virus [97]. More recently the TCR usage of these T cells found in latently infected C57BL/6 TG was characterized [98]. It was demonstrated that the majority were specific for a glycoprotein B peptide, but that $\mathrm{CD} 8^{+} \mathrm{T}$ cells specific for at least 18 other subdominant determinants could be found [98]. One caveat to these studies is that mice lacking $\mathrm{CD}^{+} \mathrm{T}$ cells display a similar latency phenotype as normal mice [14]. None the less, taken together, these observations indicate that $\mathrm{CD}^{+} \mathrm{T}$ cells are likely involved in maintaining latency but that other factors are also involved.

\section{Vaccination in HSK}

Many attempts have been made to develop a vaccine that is effective in preventing HSK. While most vaccines prevent primary HSK in animal models when given prior to infection [99-103], they typically fail when delivered therapeutically to prevent recurrent HSK $[9,104]$. Nesburn et al. reported that periocular vaccination of latently infected rabbits with recombinant HSV-2 gB/gD in MTP-PE adjuvant resulted in a 2-3-fold decrease in spontaneous corneal viral shedding but had no effect on corneal scarring [105]. They also reported that periocular vaccination with $\mathrm{gD} 1$ or $\mathrm{gD} 2$ inhibited recurrent dendritic keratitis [106]. Likewise, we and others have shown that vaccination with certain HSV-1 components limits both viral pathogenesis and prevents primary and recurrent corneal disease only when administered prior to infection $[9,104]$. If administered following infection these vaccines are ineffective in preventing recurrent disease [9]. These studies illustrate the difficulty of developing effective vaccines for both primary and recurrent infections of HSV. The development of such a vaccine would be of great clinical significance since most patients who present with HSK are latently infected $[1,6,7]$. This was illustrated by a clinical trial in which the vaccine was only effective in women who had never been infected with either HSV-1 or HSV-2 and ineffective in those who had a history of infections with either HSV-1 or HSV-2 [107]. That said, we reported that vaccination with a vhs-defective mutant of HSV-1 [108], which had previously been shown to significantly reduce the rate of reactivation $[103,104]$, would also reduce recurrent HSK when constructed with [109] or without ICP8 [81]. The important thing about these studies was that the vaccine was administered intraperitoneally after infection and thus would have therapeutic value for latently infected individuals. It should be noted that another vaccine construct that consisted of defective $v h s$ and ICP8 to which was cloned B7-1 or B7-2 was also effective prophylactically [110] and might also show efficacy when used therapeutically since it is very similar to previous vaccine constructs [81, 109]. Similar results were also seen in studies by Richards et al. who nasally vaccinated latently infected mice with a mixture of HSV-1 glycoproteins and recombinant E. coli heat-labile enterotoxin B subunit as an adjuvant [111].

The mechanism responsible for the therapeutic success of these vaccine constructs has not been fully defined. However, the mechanism could be similar to what was reported in studies involving Theiler's virus- (TMEV-) mediated demyelinating disease in mice. This disease, which is associated with a Th1 antiviral response, was shown to be significantly reduced in infected mice following vaccination with TMEV-coupled spleen cells $[112,113]$. These investigators went on to demonstrate that protection is accompanied by a preferential reduction in the Th1 antiviral response and a concomitant increase in the $\mathrm{Th} 2$-mediated antiviral response [113]. Thus it appears that protection involves alteration of a Th1-mediated immune response to one primarily mediated by Th2 cells. Results from our vaccination studies using a vhs defective replication incompetent virus show similar changes as evidenced by lower DTH responses and increased antiHSV-1 neutralizing antibody titers in vaccinated mice as compared to mice receiving a control vaccine [81]. Ocular HSV-1 infection typically stimulates an immune response that protects the animal from lethal disease by this virus but also leads to a significant inflammatory response in the cornea that can result in corneal damage. A similar type of immune response also protects latently infected animals that are reactivated from lethal viral disease but can result in significant corneal disease. The mechanism underlying this alteration in the immune response might involve the activation of $\mathrm{T}$ regulatory cells. Both conventional $\mathrm{CD}^{+} \mathrm{T}$ cells $[114,115]$ and $\mathrm{CD}^{+} \mathrm{T}$ cells $[15]$ have been implicated in regulating the anti-HSV-1 response during primary HSK. However, when Devito and Hendricks tested this, they did not observe an association for $\mathrm{T}$ regulatory cells within the cornea and decreased corneal lesions [4]. Thus the case for $\mathrm{T}$ regulatory involvement in reducing or resolving primary HSK remains to be established.

\section{Concluding Remarks}

Ocular disease associated with HSV-1 infection (HSK) is the leading cause of infectious blindness and is clearly the result of an immune-mediated inflammatory attack of the cornea. We present data comparing primary and recurrent murine models that are used to study this disease. As should be evident from this discussion, these two model systems, while sharing many characteristics, are not the same. We have learned a lot about this disease from studies of primary HSK. These studies have identified many factors that are responsible for the corneal damage associated with this disease. In fact, these studies have also suggested many potential therapeutic means of treating primary HSK. However, we would argue that without testing these therapies in a recurrent model of HSK, we might be chasing things that ultimately will not prove useful in the clinic. Consequently, due to the paucity of studies investigating recurrent HSK, much research remains to be performed. Particularly concerning those aspects of primary HSK that are reflected in recurrent 
HSK and also those things that are not, we contend that a better understanding of the immunological factors, both cellular and cell-free, that underlie the development of recurrent HSK will enable us to identify potential therapies that might prove to be most effective in treating human HSK.

\section{Acknowledgments}

This work was supported by the National Institutes of Health Grants EY11885, EY16352, and EY21247 and an unrestricted grant from Research to Prevent Blindness to the Department of Ophthalmology.

\section{References}

[1] J. S. Pepose, D. A. Leib, P. M. Stuart, and E. L. Easty, "Herpes simplex virus diseases: anterior segment of the eye," in Ocular Infection and Immunity, J. S. Pepose, G. A. N. Holland, and K. R. Wilhelmus, Eds., pp. 905-932, Mosby, St. Louis, Mo, USA, 1996.

[2] J. Thomas, S. Gangappa, S. Kanangat, and B. T. Rouse, "On the essential involvement of neutrophils in the immunopathologic disease: herpetic stromal keratitis," Journal of Immunology, vol. 158, no. 3, pp. 1383-1391, 1997.

[3] J. Maertzdorf, G. M. Verjans, L. Remeijer, A. van der Kooi, and A. D. Osterhaus, "Restricted T cell receptor beta-chain variable region protein use by cornea-derived $\mathrm{CD}^{+}$and $\mathrm{CD}^{+}$herpes simplex virus-specific T cells in patients with herpetic stromal keratitis," Journal of Infectious Diseases, vol. 187, no. 4, pp. 550-558, 2003.

[4] S. J. Divito and R. L. Hendricks, "Activated inflammatory infiltrate in HSV-1-infected corneas without herpes stromal keratitis," Investigative Ophthalmology and Visual Science, vol. 49, no. 4, pp. 1488-1495, 2008.

[5] J. R. Rinne, S. Z. Abghari, and R. D. Stulting, "The severity of herpes simplex viral keratitis in mice does not reflect the severity of disease in humans," Investigative Ophthalmology and Visual Science, vol. 33, no. 2, pp. 268-272, 1992.

[6] T. J. Liesegang, "Herpes simplex virus epidemiology and ocular importance," Cornea, vol. 20, no. 1, pp. 1-13, 2001.

[7] K. R. Wilhelmus, D. J. Coster, and H. C. Donovan, "Prognostic indicators of herpetic keratitis. Analysis of a fiveyear observation period after corneal ulceration," Archives of Ophthalmology, vol. 99, no. 9, pp. 1578-1582, 1981.

[8] J. K. Miller, K. A. Laycock, J. A. Umphress, K. K. Hook, P. M. Stuart, and J. S. Pepose, "A comparison of recurrent and primary herpes simplex keratitis in NIH inbred mice," Cornea, vol. 15, no. 5, pp. 497-504, 1996.

[9] T. L. Keadle, K. A. Laycock, J. K. Miller et al., "Efficacy of a recombinant glycoprotein D subunit vaccine on the development of primary and recurrent ocular infection with herpes simplex virus type 1 in mice," Journal of Infectious Diseases, vol. 176, no. 2, pp. 331-338, 1997.

[10] S. D. Cook, M. J. Paveloff, J. J. Doucet, A. J. Cottingham, F. Sedarati, and J. M. Hill, "Ocular herpes simplex virus reactivation in mice latently infected with latency-associated transcript mutants," Investigative Ophthalmology and Visual Science, vol. 32, no. 5, pp. 1558-1561, 1991.

[11] C. Shimeld, T. Hill, B. Blyth, and D. Easty, "An improved model of recurrent herpetic eye disease in mice," Current Eye Research, vol. 8, no. 11, pp. 1193-1205, 1989.
[12] C. Shimeld, T. J. Hill, W. A. Blyth, and D. L. Easty, "Reactivation of latent infection and induction of recurrent herpetic eye disease in mice," Journal of General Virology, vol. 71, no. 2, pp. 397-404, 1990.

[13] C. Shimeld, T. J. Hill, W. A. Blyth, and D. L. Easty, "Passive immunization protects the mouse eye from damage after herpes simplex virus infection by limiting spread of virus in the nervous system," Journal of General Virology, vol. 71, no. 3, pp. 681-687, 1990.

[14] K. A. Laycock, S. F. Lee, R. H. Brady, and J. S. Pepose, "Characterization of a murine model of recurrent herpes simplex viral keratitis induced by ultraviolet B radiation," Investigative Ophthalmology and Visual Science, vol. 32, no. 10, pp. 2741-2746, 1991.

[15] P. M. Stuart, B. Summers, J. E. Morris, L. A. Morrison, and D. A. Leib, "CD8 ${ }^{+} \mathrm{T}$ cells control corneal disease following ocular infection with herpes simplex virus type 1," Journal of General Virology, vol. 85, no. 7, pp. 2055-2063, 2004.

[16] J. E. Morris, S. Zobell, X. T. Yin et al., "Mice with mutations in fas and fas ligand demonstrate increased herpetic stromal keratitis following corneal infection with HSV-1," Journal of Immunology, vol. 188, no. 2, pp. 793-799, 2012.

[17] N. M. Sawtell and R. L. Thompson, "Rapid in vivo reactivation of herpes simplex virus in latently infected murine ganglionic neurons after transient hyperthermia," Journal of Virology, vol. 66, no. 4, pp. 2150-2156, 1992.

[18] N. M. Sawtell, "Quantitative analysis of herpes simplex virus reactivation in vivo demonstrates that reactivation in the nervous system is not inhibited at early times postinoculation," Journal of Virology, vol. 77, no. 7, pp. 4127-4138, 2003.

[19] D. M. Neumann, P. S. Bhattacharjee, and J. M. Hill, "Sodium butyrate: a chemical inducer of in vivo reactivation of herpes simplex virus type 1 in the ocular mouse model," Journal of Virology, vol. 81, no. 11, pp. 6106-6110, 2007.

[20] C. K. Newell, S. Martin, D. Sendele, C. M. Mercadal, and B. T. Rouse, "Herpes simplex virus-induced stromal keratitis: role of T-lymphocyte subsets in immunopathology," Journal of Virology, vol. 63, no. 2, pp. 769-775, 1989.

[21] Y. H. Su, X. T. Yan, J. E. Oakes, and R. N. Lausch, "Protective antibody therapy is associated with reduced chemokine transcripts in herpes simplex virus type 1 corneal infection," Journal of Virology, vol. 70, no. 2, pp. 1277-1281, 1996.

[22] H. Ghiasi, S. Cai, G. C. Perng, A. B. Nesburn, and S. L. Wechsler, "Both $\mathrm{CD}^{+}$and $\mathrm{CD}^{+} \mathrm{T}$ cells are involved in protection against HSV-1 induced corneal scarring," British Journal of Ophthalmology, vol. 84, no. 4, pp. 408-412, 2000.

[23] R. L. Kintner and C. R. Brandt, "The effect of viral inoculum level and host age on disease incidence, disease severity, and mortality in a murine model of ocular HSV-1 infection," Current Eye Research, vol. 14, no. 2, pp. 145-152, 1995.

[24] P. S. Bhattacharjee, D. M. Neumann, T. P. Foster et al., "Effective treatment of ocular HSK with a human apolipoprotein E mimetic peptide in a mouse eye model," Investigative Ophthalmology and Visual Science, vol. 49, no. 10, pp. 42634268, 2008.

[25] R. M. Strieter, T. J. Standiford, G. B. Huffnagle, L. M. Colletti, N. W. Lukacs, and S. L. Kunkel, "“The good, the bad, and the ugly": the role of chemokines in models of human disease," Journal of Immunology, vol. 156, no. 10, pp. 3583-3586, 1996.

[26] D. D. Taub, K. Conlon, A. R. Lloyd, J. J. Oppenheim, and D. J. Kelvin, "Preferential migration of activated $\mathrm{CD} 4^{+}$and $\mathrm{CD} 8^{+}$ T cells in response to MIP- $1 \alpha$ and MIP-1 $\beta$," Science, vol. 260, no. 5106, pp. 355-358, 1993. 
[27] R. R. Tamesis, E. M. Messmer, B. A. Rice, J. E. Dutt, and C. S. Foster, "The role of natural killer cells in the development of herpes simplex virus type 1 induced stromal keratitis in mice," Eye, vol. 8, no. 3, pp. 298-306, 1994.

[28] J. F. Metcalf, D. S. Hamilton, and R. W. Reichert, "Herpetic keratitis in athymic (nude) mice," Infection and Immunity, vol. 26, no. 3, pp. 1164-1171, 1979.

[29] R. G. Russell, M. P. Nasisse, H. S. Larsen, and B. T. Rouse, "Role of T-lymphocytes in the pathogenesis of herpetic stromal keratitis," Investigative Ophthalmology and Visual Science, vol. 25, no. 8, pp. 938-944, 1984.

[30] M. Z. Doymaz and B. T. Rouse, "Herpetic stromal keratitis: an immunopathologic disease mediated by $\mathrm{CD}^{+} \mathrm{T}$ lymphocytes," Investigative Ophthalmology and Visual Science, vol. 33, no. 7, pp. 2165-2173, 1992.

[31] M. G. Niemialtowski and B. T. Rouse, "Predominance of Th1 cells in ocular tissues during herpetic stromal keratitis," Journal of Immunology, vol. 149, no. 9, pp. 3035-3039, 1992.

[32] R. L. Hendricks, M. S. P. Tao, and J. C. Glorioso, "Alterations in the antigenic structure of two major HSV-1 glycoproteins, $\mathrm{gC}$ and $\mathrm{gB}$, influence immune regulation and susceptibility to murine herpes keratitis," Journal of Immunology, vol. 142, no. 1, pp. 263-269, 1989.

[33] R. L. Hendricks and T. M. Tumpey, "Contribution of virus and immune factors to herpes simplex virus type I-induced corneal pathology," Investigative Ophthalmology and Visual Science, vol. 31, no. 10, pp. 1929-1939, 1990.

[34] T. M. Tumpey, S. H. Chen, J. E. Oakes, and R. N. Lausch, "Neutrophil-mediated suppression of virus replication after herpes simplex virus type 1 infection of the murine cornea," Journal of Virology, vol. 70, no. 2, pp. 898-904, 1996.

[35] J. Thomas, S. Gangappa, S. Kanangat, and B. T. Rouse, "On the essential involvement of neutrophils in the immunopathologic disease: herpetic stromal keratitis," Journal of Immunology, vol. 158, no. 3, pp. 1383-1391, 1997.

[36] J. K. Miller, K. A. Laycock, M. M. Nash, and J. S. Pepose, "Corneal Langerhans cell dynamics after herpes simplex virus reactivation," Investigative Ophthalmology and Visual Science, vol. 34, no. 7, pp. 2282-2290, 1993.

[37] D. N. Cook, M. A. Beck, T. M. Coffman et al., "Requirement of MIP- $1 \alpha$ for an inflammatory response to viral infection," Science, vol. 269, no. 5230, pp. 1583-1585, 1995.

[38] T. M. Tumpey, H. Cheng, D. N. Cook, O. Smithies, J. E. Oakes, and R. N. Lausch, "Absence of macrophage inflammatory protein- $1 \alpha$ prevents the development of blinding herpes stromal keratitis," Agricultural and Forest Meteorology, vol. 97, no. 5, pp. 275-292, 1999.

[39] X. T. Yan, T. M. Tumpey, S. L. Kunkel, J. E. Oakes, and R. N. Lausch, "Role of MBP-2 in neutrophil migration and tissue injury in the herpes simplex virus-1-infected cornea," Investigative Ophthalmology and Visual Science, vol. 39, no. 10, pp. 1854-1862, 1998.

[40] P. M. Stuart, J. E. Morris, M. Sidhu, and T. L. Keadle, "CCL3 protects mice from corneal pathology during recurrent HSV1 infection," Frontiers in Bioscience, vol. 13, no. 12, pp. 44074415, 2008.

[41] L. Colantonio, H. Recalde, F. Sinigaglia, and D. D'Ambrosio, "Modulation of chemokine receptor expression and chemotactic responsiveness during differentiation of human naive $\mathrm{T}$ cells into Th1 or Th2 cells," European Journal of Immunology, vol. 32, no. 5, pp. 1264-1273, 2002.

[42] R. R. Fenton, S. Molesworth-Kenyon, J. E. Oakes, and R. N. Lausch, "Linkage of IL-6 with neutrophil chemoattractant expression in virus-induced ocular inflammation," Investigative Ophthalmology and Visual Science, vol. 43, no. 3, pp. 737743, 2002.

[43] T. M. Tumpey, H. Cheng, X. T. Yan, J. E. Oakes, and R. N. Lausch, "Chemokine synthesis in the HSV-1-infected cornea and its suppression by interleukin-10," Journal of Leukocyte Biology, vol. 63, no. 4, pp. 486-492, 1998.

[44] B. Kim, P. P. Sarangi, Y. Lee, S. D. Kaistha, S. Lee, and B. T. Rouse, "Depletion of MCP-1 increases development of herpetic stromal keratitis by innate immune modulation," Journal of Leukocyte Biology, vol. 80, no. 6, pp. 1405-1415, 2006.

[45] S. K. Eo, S. Lee, S. Chun, and B. T. Rouse, "Modulation of immunity against herpes simplex virus infection via mucosal genetic transfer of plasmid DNA encoding chemokines," Journal of Virology, vol. 75, no. 2, pp. 569-578, 2001.

[46] S. K. Lee, B. K. Choi, W. J. Kang et al., "MCP-1 derived from stromal keratocyte induces corneal infiltration of $\mathrm{CD}^{+} \mathrm{T}$ cells in herpetic stromal keratitis," Molecules and Cells, vol. 26, no. 1, pp. 67-73, 2008.

[47] R. Duan, L. Remeijer, J. M. van Dun, A. D. Osterhaus, and G. M. Verjans, "Granulocyte macrophage colony-stimulating factor expression in human herpetic stromal keratitis: Implications for the role of neutrophils in HSK," Investigative Ophthalmology and Visual Science, vol. 48, no. 1, pp. 277-284, 2007.

[48] Z. Mikloska, V. A. Danis, S. Adams, A. R. Lloyd, D. L. Adrian, and A. L. Cunningham, "In vivo production of cytokines and $\beta(\mathrm{C}-\mathrm{C})$ chemokines in human recurrent herpes simplex lesions-do herpes simplex virus-infected keratinocytes contribute to their production?" Journal of Infectious Diseases, vol. 177, no. 4, pp. 827-838, 1998.

[49] H. Li, J. Zhang, A. Kumar, M. Zheng, S. S. Atherton, and F. S. Yu, "Herpes simplex virus 1 infection induces the expression of proinflammatory cytokines, interferons and TLR7 in human corneal epithelial cells," Immunology, vol. 117, no. 2, pp. 167-176, 2006.

[50] J. H. Dufour, M. Dziejman, M. T. Liu, J. H. Leung, T. E. Lane, and A. D. Luster, "IFN- $\gamma$-inducible protein 10 (IP-10; CXCL10)-deficient mice reveal a role for IP-10 in effector T cell generation and trafficking," Journal of Immunology, vol. 168, no. 7, pp. 3195-3204, 2002.

[51] S. Lee, M. Zheng, S. Deshpande, S. K. Eo, T. A. Hamilton, and B. T. Rouse, "IL-12 suppresses the expression of ocular immunoinflammatory lesions by effects on angiogenesis," Journal of Leukocyte Biology, vol. 71, no. 3, pp. 469-476, 2002.

[52] D. J. Carr, J. Chodosh, J. Ash, and T. E. Lane, "Effect of antiCXCL10 monoclonal antibody on herpes simplex virus type 1 keratitis and retinal infection," Journal of Virology, vol. 77, no. 18, pp. 10037-10046, 2003.

[53] H. F. Staats and R. N. Lausch, "Cytokine expression in vivo during murine herpetic stromal keratitis: effect of protective antibody therapy," Journal of Immunology, vol. 151, no. 1, pp. 277-283, 1993.

[54] P. S. Biswas, K. Banerjee, B. Kim, and B. T. Rouse, "Mice transgenic for IL-1 receptor antagonist protein are resistant to herpetic stromal keratitis: possible role for IL-1 in herpetic stromal keratitis pathogenesis," Journal of Immunology, vol. 172, no. 6, pp. 3736-3744, 2004.

[55] A. Suryawanshi, T. Veiga-Parga, N. K. Rajasagi et al., "Role of il-17 and th17 cells in herpes simplex virus-induced corneal immunopathology," Journal of Immunology, vol. 187, no. 4, pp. 1919-1930, 2011. 
[56] T. L. Keadle, K. A. Laycock, J. S. Pepose, and P. M. Stuart, "Proinflammatory cytokines IL- 1 and TNF- $\alpha$ are required for recurrent herpetic keratitis in NIH mice," Investigative Ophthalmology \& Visual Science, vol. 41, pp. 96-102, 2000.

[57] J. S. Babu, S. Kanangat, and B. T. Rouse, "T cell cytokine mRNA expression during the course of the immunopathologic ocular disease herpetic stromal keratitis," Journal of Immunology, vol. 154, no. 9, pp. 4822-4829, 1995.

[58] S. Kanangat, J. Thomas, S. Gangappa, J. S. Babu, and B. T. Rouse, "Herpes simplex virus type 1-mediated up-regulation of IL-12 (p40) mRNA expression: implications in immunopathogenesis and protection," Journal of Immunology, vol. 156, no. 3, pp. 1110-1116, 1996.

[59] C. Shimeld, D. L. Easty, and T. J. Hill, "Reactivation of herpes simplex virus type 1 in the mouse trigeminal ganglion: an in vivo study of virus antigen and cytokines," Journal of Virology, vol. 73, no. 3, pp. 1767-1773, 1999.

[60] T. L. Keadle, N. Usui, K. A. Laycock, Y. Kumano, J. S. Pepose, and P. M. Stuart, "Cytokine expression in murine corneas during recurrent herpetic stromal keratitis," Ocular Immunology and Inflammation, vol. 9, no. 3, pp. 193-205, 2001.

[61] T. H. Stumpf, C. Shimeld, D. L. Easty, and T. J. Hill, "Cytokine production in a murine model of recurrent herpetic stromal keratitis," Investigative Ophthalmology and Visual Science, vol. 42, no. 2, pp. 372-378, 2001.

[62] T. R. Mosmann and R. L. Coffman, "TH1 and TH2 cells: different patterns of lymphokine secretion lead to different functional properties," Annual Review of Immunology, vol. 7, pp. 145-173, 1989.

[63] K. E. Graeber and N. J. Olsen, "Th17 cell cytokine secretion profile in host defense and autoimmunity," Inflammation Research, vol. 61, no. 2, pp. 87-96, 2012.

[64] R. L. Hendricks, T. M. Tumpey, and A. Finnegan, "IFN- $\gamma$ and IL-2 are protective in the skin but pathologic in the corneas of HSV-1-infected mice," Journal of Immunology, vol. 149, no. 9, pp. 3023-3028, 1992.

[65] Q. Tang, W. Chen, and R. L. Hendricks, "Proinflammatory functions of IL-2 in herpes simplex virus corneal infection," Journal of Immunology, vol. 158, no. 3, pp. 1275-1283, 1997.

[66] K. Banerjee, P. S. Biswas, and B. T. Rouse, "Role of Stat4mediated signal transduction events in the generation of aggressor $\mathrm{CD}^{+}{ }^{+} \mathrm{T}$ cells in herpetic stromal keratitis pathogenesis," Journal of Interferon and Cytokine Research, vol. 27, no. 1, pp. 65-75, 2007.

[67] D. M. Bouley, S. Kanangat, W. Wire, and B. T. Rouse, "Characterization of herpes simplex virus type-1 infection and herpetic stromal keratitis development in IFN- $\gamma$ knockout mice," Journal of Immunology, vol. 155, no. 8, pp. 3964-3971, 1995.

[68] N. G. Jacobson, S. J. Szabo, R. M. Weber-Nordt et al., "Interleukin 12 signaling in $\mathrm{T}$ helper type 1 (Th1) cells involves tyrosine phosphorylation of signal transducer and activator of transcription (Stat)3 and Stat4," Journal of Experimental Medicine, vol. 181, no. 5, pp. 1755-1762, 1995.

[69] T. L. Keadle, D. E. Alexander, D. A. Leib, and P. M. Stuart, "Interferon gamma is not required for recurrent herpetic stromal keratitis," Virology, vol. 380, no. 1, pp. 46-51, 2008.

[70] T. M. Tumpey, V. M. Elner, S. H. Chen, J. E. Oakes, and R. N. Lausch, "Interleukin-10 treatment can suppress stromal keratitis induced by herpes simplex virus type 1," Journal of Immunology, vol. 153, no. 5, pp. 2258-2265, 1994.

[71] M. Daheshia, N. Kuklin, S. Kanangat, E. Manickan, and B. T. Rouse, "Suppression of ongoing ocular inflammatory disease by topical administration of plasmid DNA encoding IL-10," Journal of Immunology, vol. 159, no. 4, pp. 1945-1952, 1997.

[72] T. L. Keadle and P. M. Stuart, "Interleukin-10 (IL-10) ameliorates corneal disease in a mouse model of recurrent herpetic keratitis," Microbial Pathogenesis, vol. 38, no. 1, pp. 13-21, 2005.

[73] S. J. Molesworth-Kenyon, R. Yin, J. E. Oakes, and R. N. Lausch, "IL-17 receptor signaling influences virus-induced corneal inflammation," Journal of Leukocyte Biology, vol. 83, no. 2, pp. 401-408, 2008.

[74] N. K. Rajasagi, P. B. Reddy, A. Suryawanshi, S. Mulik, P. Gjorstrup, and B. T. Rouse, "Controlling herpes simplex virus-induced ocular inflammatory lesions with the lipidderived mediator resolvin E1," Journal of Immunology, vol. 186, no. 3, pp. 1735-1746, 2011.

[75] A. J. Lepisto, G. M. Frank, M. Xu, P. M. Stuart, and R. L. Hendricks, "CD8 T cells mediate transient herpes stromal keratitis in CD4-deficient mice," Investigative Ophthalmology and Visual Science, vol. 47, no. 8, pp. 3400-3409, 2006.

[76] D. Bauer, S. Mrzyk, N. Van Rooijen, K. P. Steuhl, and A. Heiligenhaus, "Incidence and severity of herpetic stromal keratitis: impaired by the depletion of lymph node macrophages," Experimental Eye Research, vol. 72, no. 3, pp. 261-269, 2001.

[77] L. Xia, S. Zhang, J. Zhou, and Y. Li, "A crucial role for B and $\mathrm{T}$ lymphocyte attenuator in preventing the development of $\mathrm{CD}^{+} \mathrm{T}$ cell-mediated herpetic stromal keratitis," Molecular Vision, vol. 16, pp. 2071-2083, 2010.

[78] A. Heiligenhaus, H. Li, A. Schmitz, S. Wasmuth, and D. Bauer, "Improvement of herpetic stromal keratitis with fumaric acid derivate is associated with systemic induction of Thelper 2 cytokines," Clinical and Experimental Immunology, vol. 142, no. 1, pp. 180-187, 2005.

[79] T. L. Keadle, J. L. Morris, J. S. Pepose, and P. M. Stuart, "CD4 ${ }^{+}$ and $\mathrm{CD}^{+}$cells are key participants in the development of recurrent herpetic stromal keratitis in mice," Microbial Pathogenesis, vol. 32, no. 6, pp. 255-262, 2002.

[80] E. Chang, L. Galle, D. Maggs, D. M. Estes, and W. J. Mitchell, "Pathogenesis of herpes simplex virus type 1-induced corneal inflammation in perforin-deficient mice," Journal of Virology, vol. 74, no. 24, pp. 11832-11840, 2000.

[81] T. L. Keadle, L. A. Morrison, J. L. Morris, J. S. Pepose, and P. M. Stuart, "Therapeutic immunization with a virion host shutoff-defective, replication-incompetent herpes simplex virus type 1 strain limits recurrent herpetic ocular infection," Journal of Virology, vol. 76, no. 8, pp. 3615-3625, 2002.

[82] E. R. Kearney, T. L. Walunas, R. W. Karr et al., "Antigendependent clonal expansion of a trace population of antigenspecific $\mathrm{CD}^{+} \mathrm{T}$ cells in vivo is dependent on $\mathrm{CD} 28$ costimulation and inhibited by CTLA-4," Journal of Immunology, vol. 155, no. 3, pp. 1032-1036, 1995.

[83] S. Gangappa, E. Manickan, and B. T. Rouse, "Control of herpetic stromal keratitis using CTLA4Ig fusion protein," Clinical Immunology and Immunopathology, vol. 86, no. 1, pp. 88-94, 1998.

[84] Y. Osorio, S. Cai, and H. Ghiasi, "Treatment of mice with anti-CD86 mAb reduces CD8+ T cell-mediated CTL activity and enhances ocular viral replication in HSV-1-infected mice," Ocular Immunology and Inflammation, vol. 13, no. 23, pp. 159-167, 2005.

[85] M. Xu, A. J. Lepisto, and R. L. Hendricks, "CD154 signaling regulates the Th1 response to herpes simplex virus-1 and inflammation in infected corneas," Journal of Immunology, vol. 173, no. 2, pp. 1232-1239, 2004. 
[86] A. J. Lepisto, M. Xu, H. Yagita, A. D. Weinberg, and R. L. Hendricks, "Expression and function of the $\mathrm{OX}_{40} / \mathrm{OX}_{40} \mathrm{~L}$ costimulatory pair during herpes stromal keratitis," Journal of Leukocyte Biology, vol. 81, no. 3, pp. 766-774, 2007.

[87] S. K. Seo, H. Y. Park, J. H. Choi et al., "Blocking 4-1BB/41BB ligand interactions prevents herpetic stromal keratitis," Journal of Immunology, vol. 171, no. 2, pp. 576-583, 2003.

[88] Y. H. Kim, S. K. Seo, B. K. Choi et al., " $4-1 B B$ costimulation enhances HSV-1-specific $\mathrm{CD}^{+} \mathrm{T}$ cell responses by the induction of CD11 $\mathrm{c}^{+} \mathrm{CD} 8^{+} \mathrm{T}$ cells," Cellular Immunology, vol. 238, no. 2, pp. 76-86, 2005.

[89] T. Liu, Q. Tang, and R. L. Hendricks, "Inflammatory infiltration of the trigeminal ganglion after herpes simplex virus type 1 corneal infection," Journal of Virology, vol. 70, no. 1, pp. 264-271, 1996.

[90] T. Liu, K. M. Khanna, B. N. Carriere, and R. L. Hendricks, "Gamma interferon can prevent herpes simplex virus type 1 reactivation from latency in sensory neurons," Journal of Virology, vol. 75, no. 22, pp. 11178-11184, 2001.

[91] K. Khanna, R. Bonneau, P. Kinchington, and R. L. Hendricks, "Herpes simplex virus-specific memory $\mathrm{CD}^{+} \mathrm{T}$ cells are selectively activated and retained in latently infected sensory ganglia," Immunity, vol. 18, no. 5, pp. 593-603, 2003.

[92] V. Decman, P. R. Kinchington, S. A. Harvey, and R. L. Hendricks, "Gamma interferon can block herpes simplex virus type 1 reactivation from latency, even in the presence of late gene expression," Journal of Virology, vol. 79, no. 16, pp. 10339-10347, 2005.

[93] K. Hüfner, T. Derfuss, S. Herberger et al., "Latency of $\alpha$ herpes viruses is accompanied by a chronic inflammation in human trigeminal ganglia but not in dorsal root ganglia," Journal of Neuropathology and Experimental Neurology, vol. 65, no. 10, pp. 1022-1030, 2006.

[94] G. M. Verjans, R. Q. Hintzen, J. M. van Dun et al., "Selective retention of herpes simplex virus-specific T cells in latently infected human trigeminal ganglia," Proceedings of the National Academy of Sciences of the United States of America, vol. 104, no. 9, pp. 3496-3501, 2007.

[95] J. E. Knickelbein, K. M. Khanna, M. B. Yee, C. J. Baty, P. R. Kinchington, and R. L. Hendricks, "Noncytotoxic lytic granule-mediated $\mathrm{CD}^{+} \mathrm{T}$ cell inhibition of HSV-1 reactivation from neuronal latency," Science, vol. 322, no. 5899, pp. 268-271, 2008.

[96] G. M. Frank, A. J. Lepisto, M. L. Freeman, B. S. Sheridan, T. L. Cherpes, and R. L. Hendricks, "Early $\mathrm{CD} 4^{+} \mathrm{T}$ cell help prevents partial $\mathrm{CD}^{+} \mathrm{T}$ cell exhaustion and promotes maintenance of herpes simplex virus 1 latency," Journal of Immunology, vol. 184, no. 1, pp. 277-286, 2010.

[97] N. A. DeLuca, A. M. McCarthy, and P. A. Schaffer, "Isolation and characterization of deletion mutants of herpes simplex virus type 1 in the gene encoding immediate-early regulatory protein ICP4," Journal of Virology, vol. 56, no. 2, pp. 558-570, 1985.

[98] A. J. St. Leger, B. Peters, J. Sidney, A. Sette, and R. L. Hendricks, "Defining the herpes simplex virus-specific CD8+ T cell repertoire in C57BL/6 mice," Journal of Immunology, vol. 186, no. 7, pp. 3927-3933, 2011.

[99] H. Ghiasi, S. Bahri, A. B. Nesburn, and S. L. Wechsler, "Protection against herpes simplex virus-induced eye disease after vaccination with seven individually expressed herpes simplex virus 1 glycoproteins," Investigative Ophthalmology and Visual Science, vol. 36, no. 7, pp. 1352-1360, 1995.
[100] Heiligenhaus, P. A. Wells, and C. S. Foster, "Immunisation against HSV-1 keratitis with a synthetic gD peptide," Eye, vol. 9, no. 1, pp. 89-95, 1995.

[101] Y. Inoue, Y. Ohashi, Y. Shimomura et al., "Herpes simplex virus glycoprotein D. Protective immunity against murine herpetic keratitis," Investigative Ophthalmology and Visual Science, vol. 31, no. 3, pp. 411-418, 1990.

[102] A. B. Nesburn, R. L. Burke, H. Ghiasi, S. Slanina, and S. L. Wechsler, "Intramuscular vaccination of rabbits with expressed HSV-2 glycoproteins $\mathrm{B}+\mathrm{D}(\mathrm{gD} 2+\mathrm{gD} 2)$ protects against death following ocular HSV-1 challenge but not from eye disease," Investigative Ophthalmology \& Visual Science, vol. 35, pp. 1679-1686, 1994.

[103] J. Walker and D. A. Leib, "Protection from primary infection and establishment of latency by vaccination with a herpes simplex virus type 1 recombinant deficient in the virion host shutoff (vhs) function," Vaccine, vol. 16, no. 1, pp. 1-5, 1998.

[104] J. Walker, K. A. Laycock, J. S. Pepose, and D. A. Leib, "Postexposure vaccination with a virion host shutoff defective mutant reduces UV-B radiation-induced ocular herpes simplex virus shedding in mice," Vaccine, vol. 16, no. 1, pp. 6-8, 1998.

[105] A. B. Nesburn, R. L. Burke, H. Ghiasi, S. Slanina, S. Bahri, and S. L. Wechsler, "Vaccine therapy for ocular herpes simplex virus (HSV) infection: periocular vaccination reduces spontaneous ocular HSV type 1 shedding in latently infected rabbits," Journal of Virology, vol. 68, no. 8, pp. 5084-5092, 1994.

[106] A. B. Nesburn, R. L. Burke, H. Gbiasi, S. M. Slanina, and S. L. Wechsler, "A therapeutic vaccine that reduces recurrent herpes simplex virus type 1 corneal disease," Investigative Ophthalmology and Visual Science, vol. 39, no. 7, pp. 11631170, 1998.

[107] L. R. Stanberry, S. L. Spruance, A. L. Cunningham et al., "Glycoprotein-D-adjuvant vaccine to prevent genital herpes," The New England Journal of Medicine, vol. 347, no. 21, pp. 1652-1661, 2002.

[108] L. I. Strelow and D. A. Leib, "Role of the virion host shutoff (vhs) of herpes simplex virus type 1 in latency and pathogenesis," Journal of Virology, vol. 69, no. 11, pp. 67796786, 1995.

[109] T. L. Keadle, J. Walker, K. A. Laycock et al., "Therapeutic vaccination with vhs- herpes simplex virus (HSV) reduces severity of recurrent herpetic stromal keratitis in mice," Journal of General Virology, vol. 83, no. 10, pp. 2361-2365, 2002.

[110] J. E. Schrimpf, E. M. Tu, H. Wang, Y. M. Wong, and L. A. Morrison, "B7 costimulation molecules encoded by replication-defective, vhs-deficient HSV-1 improve vaccineinduced protection against corneal disease," Plos ONE, vol. 6, no. 8, 2011.

[111] C. M. Richards, R. Case, T. R. Hirst, T. J. Hill, and N. A. Williams, "Protection against recurrent ocular herpes simplex virus type 1 disease after therapeutic vaccination of latently infected mice," Journal of Virology, vol. 77, no. 12, pp. 6692-6699, 2003.

[112] W. J. Karpus, J. G. Pope, J. D. Peterson, M. C. Dal Canto, and S. D. Miller, "Inhibition of Theiler's virus-mediated demyelination by peripheral immune tolerance induction," Journal of Immunology, vol. 155, no. 2, pp. 947-957, 1995.

[113] W. J. Karpus, J. D. Peterson, and S. D. Miller, "Anergy in vivo: down-regulation of antigen-specific $\mathrm{CD}^{+}{ }^{+} \mathrm{T}_{h} 1$ but not $\mathrm{T}_{h} 2$ 
cytokine responses," International Immunology, vol. 6, no. 5, pp. 721-730, 1994.

[114] P. P. Sarangi, S. Sehrawat, S. Suvas, and B. T. Rouse, "IL10 and natural regulatory $\mathrm{T}$ cells: two independent antiinflammatory mechanisms in herpes simplex virus-induced ocular immunopathology," Journal of Immunology, vol. 180, no. 9, pp. 6297-6306, 2008.

[115] S. SehraWat and B. T. Rouse, "Anti-inflammatory effects of FTY720 against viral-induced immunopathology: role of drug-induced conversion of $\mathrm{T}$ cells to become Foxp3+ regulators," Journal of Immunology, vol. 180, no. 11, pp. 7636-7647, 2008. 


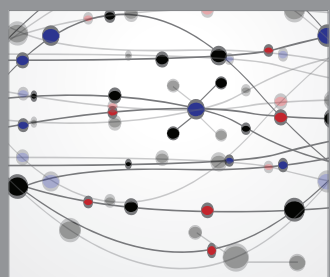

The Scientific World Journal
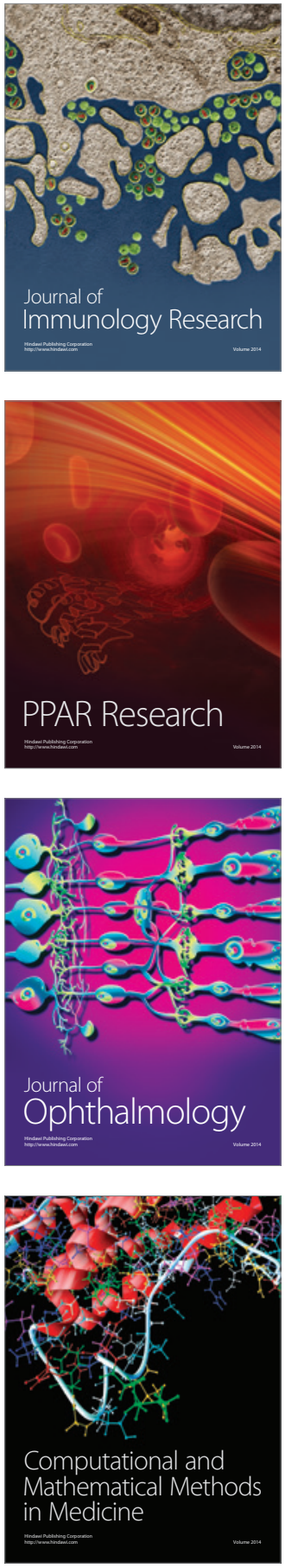

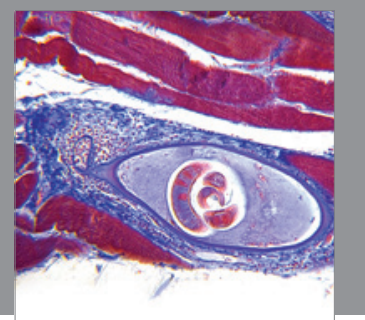

Gastroenterology

Research and Practice
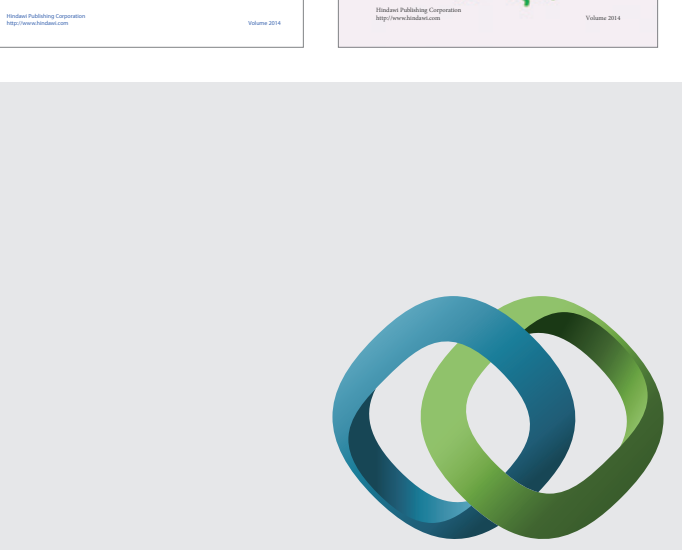

\section{Hindawi}

Submit your manuscripts at

http://www.hindawi.com
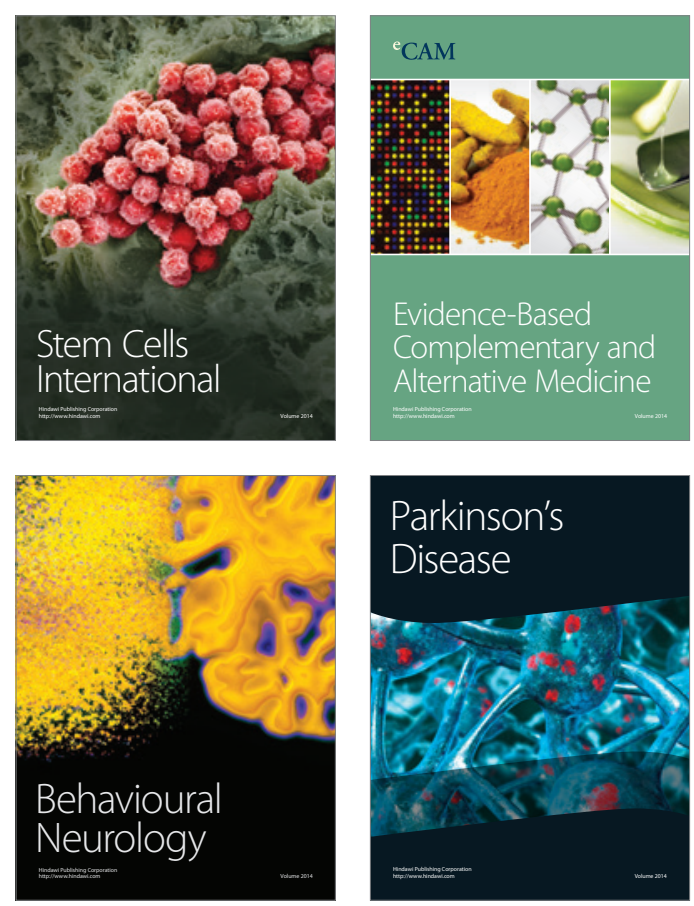

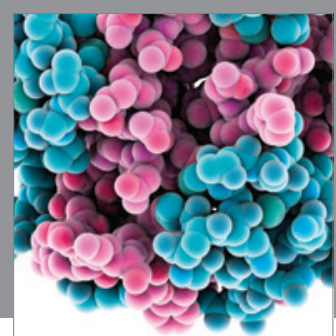

Journal of
Diabetes Research

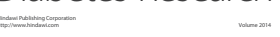

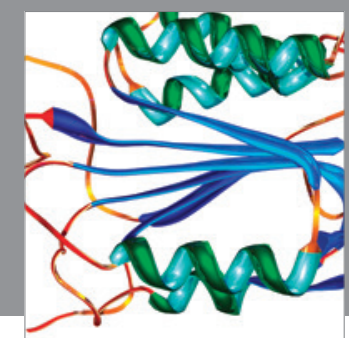

Disease Markers
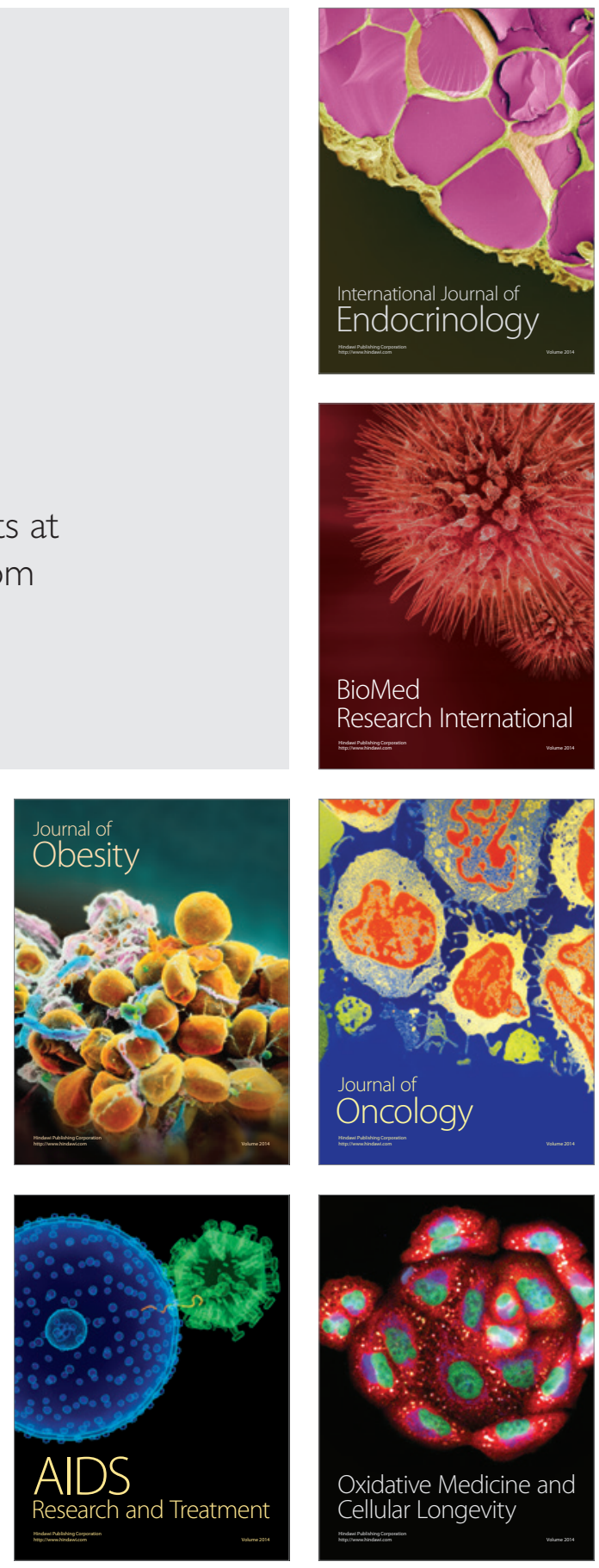